\title{
Do Grades Shape Students' School Engagement? The Psychological Consequences of Report Card Grades at the Beginning of Secondary School
}

\author{
Astrid M. G. Poorthuis \\ Utrecht University and University of Amsterdam \\ Sander Thomaes \\ Utrecht University and University of Southampton
}

\author{
Jaana Juvonen \\ University of California at Los Angeles
}

Jaap J. A. Denissen

Tilburg University

\author{
Bram Orobio de Castro and Marcel A. G. van Aken \\ Utrecht University
}

\begin{abstract}
Receiving report card grades is psychologically salient to most students and can elicit a range of affective reactions. A 3-wave longitudinal study examined how grades shape students' $(N=375 ; M$ age at Wave $1=12.6$ years) school engagement through the affective reactions they elicit. Emotional and behavioral engagement were measured at the start of secondary school and 6 months later. Halfway through this period, students' positive and negative affective reactions to their 1st report card in secondary school were assessed. As expected, lower report card grades predicted lower emotional and behavioral engagement in spring, when controlling for prior levels of engagement. These links were mediated by students' affective reactions. Boys and children who perceived the performance norms in their class to be high were more affectively reactive to their grades, which resulted in a stronger indirect effect of grades via negative affect on emotional engagement. Complementing the traditional view that grades are consequences of school engagement, the current findings suggest that grades function also as antecedents of school engagement.
\end{abstract}

Keywords: school engagement, positive and negative affect, grades, school transition, school performance

Throughout the world, students typically receive grades as an evaluation of their school work. Grades are not only a form of feedback on past performance, they also impact subsequent academic trajectories by determining whether students graduate from one grade to the next, and what level of course work (e.g., low or

This article was published Online First October 27, 2014.

Astrid M. G. Poorthuis, Department of Developmental Psychology, Utrecht University, and Research Institute of Child Development and Education, University of Amsterdam; Jaana Juvonen, Department of Developmental Psychology, University of California at Los Angeles; Sander Thomaes, Department of Developmental Psychology, Utrecht University, and Department of Psychology, University of Southampton; Jaap J. A. Denissen, Department of Developmental Psychology, Tilburg University; Bram Orobio de Castro, Department of Psychology, Utrecht University; Marcel A. G. van Aken, Department of Developmental Psychology, Utrecht University.

This research was supported by a grant from the Jo Kolk Stichting and a Utrecht University Travel Grant.

Correspondence concerning this article should be addressed to Astrid M. G. Poorthuis, Research Institute of Child Development and Education, P.O. Box 15780, 1001 NG Amsterdam, the Netherlands. E-mail: a.m.g .poorthuis@uva.nl high academic track) is available to them. Given the importance of grades, it is not surprising that they can trigger a range of affective reactions, from excitement and pride to distress and shame (Crocker, Karpinski, Quinn, \& Chase, 2003; Goldstein \& Strube, 1994; Kluger \& DeNisi, 1996). Grades and the affective reactions they evoke likely affect how much time and effort students invest in their subsequent work. Although at times teachers may expect that low grades urge students to put more effort in their school work (Kohn, 1994), there is some empirical research suggesting that it may be high rather than low grades that are more effective in increasing student effort (You \& Sharkey, 2009) and interest in the subject matter (Butler, 1988; Denissen, Zarrett, \& Eccles, 2007; Shim \& Ryan, 2005). Thus, the motivational effects of grades may differ from their presumed effects, possibly in part because of the motivational consequences of the affective reactions they evoke.

How grades shape students' school engagement through the affective reactions they elicit is the question addressed in the current study. In spite of a growing body of research showing that achievement-related emotions (e.g., anxiety, pride) play an important role in student learning (Linnenbrink-Garcia \& Pekrun, 2011), there is paucity of research linking grades, affective reactions, and student engagement. Research on such interconnections may be 
especially informative at critical time points, such as after the transition from primary school to secondary school, ${ }^{1}$ when students are uncertain about how their academic competencies and performance will match up to what is expected from them (Harter, Whitesell, \& Kowalski, 1992). Research shows that students' grades tend to fall off in sixth grade (i.e., the first year after the school transition in the United States), possibly because of stricter grading compared to primary school (Barber \& Olsen, 2004; Eccles et al., 1993; Zanobini \& Usai, 2002). At the same time, school engagement also declines for many students (Eccles et al., 1993; Fredricks \& Eccles, 2002; Maulana, Opdenakker, Stroet, \& Bosker, 2012). We propose that students' affective reactions to grades might help explain how and why grades impact subsequent student engagement.

\section{School Engagement}

School engagement-students' active involvement in school based activities (Fredricks, Blumenfeld, \& Paris, 2004; Skinner, Furrer, Marchand, \& Kindermann, 2008)—is one of the strongest predictors of academic success and failure, including school dropout, retention, and achievement (Alexander, Entwisle, \& Horsey, 1997; Connell, Spencer, \& Aber, 1994; Fredricks et al., 2004). Two overlapping but empirically distinguishable components of school engagement are behavioral engagement and emotional engagement (Li \& Lerner, 2011; Fredricks et al., 2004). Behavioral engagement refers to overt behavior, such as active class participation, effort and attention during classroom activities (Skinner et al., 2008), whereas emotional engagement more strongly refers to psychological experience, such as interest, enthusiasm, and (lack of) boredom (Skinner et al., 2008). ${ }^{2}$ Most students show decreases in both behavioral and emotional engagement from childhood into adolescence, with the steepest decline after the transition from primary to secondary school (i.e., in sixth grade; Eccles et al., 1993; Fredricks \& Eccles, 2002). Yet such decreasing trajectories are not universal (e.g., Li \& Lerner, 2011), and so research on the processes that might help account for engagement at the beginning of secondary school is critical.

There are some initial indications that grades may help understand changes in student engagement. In a longitudinal study among adolescents (You \& Sharkey, 2009), grades were a better predictor of change in behavioral engagement over time than were other relevant variables (including parental expectations, parentchild communication, locus of control, self-concept, peer academic value, whether a friend dropped out of school, and college aspirations), with higher grades predicting increased behavioral engagement. Grades have also been related to changes in emotional engagement. For example, college students who received high grades showed increased emotional engagement over the course of a semester (Shim \& Ryan, 2005). Other studies in both primary and secondary school have demonstrated concurrent positive associations between students' grades and their behavioral and emotional engagement (e.g., Marks, 2000; Skinner, Wellborn, \& Connell, 1990; Trautwein, Lüdtke, Marsh, Koller, \& Baumert, 2006)

\section{Role of Affective Reactions}

What could be the mechanism through which grades influence school engagement? Motivational theories, such as expectancy- value theory (Wigfield \& Eccles, 2000) and self-efficacy theory (Bandura, 1977) highlight the role of cognitive processes as predictors of school engagement. In addition, grades may elicit powerful emotions (Crocker et al., 2003; Goldstein \& Strube, 1994; Kluger \& DeNisi, 1996). These affective processes have received far less attention to date (Linnenbrink-Garcia \& Pekrun, 2011).

The present study aims to address this knowledge gap by testing the proposition that grades predict school engagement through the positive and negative affective reactions they elicit. Positive affect (Watson, Clark, \& Tellegen, 1988) captures arousing pleasant and alert mood states, such as excitement, enthusiasm, and pride. Lack of positive affect is characterized by lethargy. Negative affect, on the other hand, captures arousing aversive mood states, such as distress, shame, and fear. Lack of negative affect is characterized by calmness (Watson et al., 1988). Previous research has established that positive and negative affect are relatively independent affect dimensions that only are moderately negatively correlated (Goldstein \& Stube, 1994; Tellegen, Watson, \& Clark, 1999).

Positive and negative affect are theorized to be part of two general affective activation systems - an approach system and a withdrawal system (Watson, Wiese, Vaidya, \& Tellegen, 1999). Positive affect is theorized to be part of a larger motivational system of approach tendencies (Watson et al., 1999). As such, the positive affective reactions that result from high grades are expected to facilitate school engagement, both its emotional and behavioral manifestations. Although this link has not yet been tested in the context of receiving grades, previous empirical work on positive affect in other academic contexts (e.g., during group work and while making homework) is consistent with such a view (Efklides \& Petkaki, 2005; Linnenbrink-Garcia, Rogat, \& Koskey, 2011; Pekrun, Goetz, Frenzel, Barchfeld, \& Perry, 2011; Pekrun, Goetz, Titz, \& Perry, 2002).

Negative affect is theorized to be part of a larger motivational system of withdrawal tendencies that help people to avoid aversive stimuli (Watson et al., 1999). Predictions for negative affect may be different for emotional and behavioral engagement. Negative affect tends to be incompatible with feelings of enjoyment and interest (Pekrun et al., 2002). It is therefore likely that the negative affective reactions that result from low school grades will compromise students' emotional engagement - their interest and enjoyment during classroom activities. Indeed, some prior studies have found that negative affect is associated with lower emotional engagement (e.g., Martin, 2011; Pekrun et al., 2002).

Regarding behavioral school engagement, we propose that negative affect may have ambivalent effects. Negative affect may be an impetus to withdraw from the situation that caused the negative feelings (Watson et al., 1999). As students are obliged to attend school, they may not be able to withdraw from the situation physically but may withdraw psychologically, such as by decreasing the effort they invest in their schoolwork. Consistent with that

\footnotetext{
${ }^{1}$ In the Dutch school system, students make the transition from primary school into secondary school between sixth and seventh grade, at the age of 12 .

${ }^{2}$ An additional component of engagement (not considered in the present study) is cognitive engagement (e.g., Fredrick et al., 2004). An alternative model of student engagement by Pekrun and Linnenbrink-Garcia (2012) distinguishes five components: cognitive, motivational, behavioral, cognitive behavioral, and social-behavioral engagement.
} 
view, negative affect has been specifically linked to lower behavioral engagement in some previous studies (Dettmers et al., 2011; Linnenbrink-Garcia et al., 2011). However, negative affect may be motivating some students to overcome an aversive state and avoid future failure by investing extra effort in their schoolwork (Pekrun et al., 2002; Pekrun \& Linnenbrink-Garcia, 2012). Indeed, some studies have shown that negative feelings, including anxiety and shame, sometimes encourage people to try harder in both academic and nonacademic domains (Eysenck, Derakshan, Santos, \& Calvo, 2007; Martin, 2011; Tangney \& Dearing, 2003; Tulis \& Fulmer, 2013; Turner \& Schallert, 2001). Given these mixed findings, we did not predict main effects of negative affect on behavioral engagement.

\section{Moderating Factors: Performance Norms and Gender}

Students do not receive their grades in a social vacuum but are likely to compare their performance to the performance of their classmates (Pulfrey, Buchs, \& Butera, 2011; Trautwein et al., 2006). Hence, when considering affective reactions to grades and how these predict subsequent engagement, it is important to consider students' perceptions of the performance norms in their classroom-i.e., what grades they think their classmates on average obtain. Prior research suggests that adolescents are particularly prone to adapt to peer academic norms shortly after the secondary school transition (Masten, Juvonen, \& Spatzier, 2009; Molloy, Gest, \& Rulison, 2011). Thus, when students perceive performance norms in their classroom to be high, they may hold higher standards for their own performance as well. Consequently, report card grades may elicit stronger affective reactions in students who perceive the norms in their class to be high than in students who perceive the performance norms in their class to be low.

When studying affective reactions to receiving grades and school engagement, it is also important to consider possible gender differences. Numerous studies have shown that compared to adolescent boys, adolescent girls typically obtain higher school grades (e.g., Duckworth \& Seligman, 2006; Hendriks, Kuyper, Lubbers, \& van der Werf, 2011; Lam et al., 2012; Wampler, Munsch, \& Adams, 2002) and also report higher levels of school engagement (e.g., Lam et al., 2012; Li \& Lerner, 2011; Marks, 2000; Rozendaal, Minnaert, \& Boekaerts, 2001; Wang, Willett, \& Eccles, 2011). Studying children's affective reactivity and subsequent engagement following the reception of grades could provide some insights into these gender differences. Given that boys are usually somewhat less emotionally reactive than girls (e.g., Charbonneau, Mezulis, \& Hyde, 2009; Rudolph, 2002), it may be that boys will experience weaker affective reactions than girls in response to their grades. On the other hand, adolescent boys tend to be more competitive than adolescent girls (e.g., Gneezy \& Rustichini, 2004; Hibbard \& Buhrmester, 2010), and so another possibility is that they experience stronger affective reactions to grades. In the present study, these two different possibilities regarding the moderating role of gender are explored.

\section{Present Study}

To study the effects of grades on affect and engagement, we conducted a three-wave longitudinal study among Dutch young adolescents who just made the transition to secondary school. A conceptual model of the study is provided in Figure 1. We studied students' affective reactions to their first report card and subsequent engagement during the first semester in secondary school. In the Dutch secondary school system, students are grouped into different academic tracks, ranging from practical training to preuniversity education (for a more detailed account of the Dutch school system, see Hendriks et al., 2011). Placement with a more academically homogeneous group of classmates may change the relative position of children in the peer group and the grades they receive. Therefore, during the first semester in secondary school, report card grades might have particularly strong psychological impact.

The first aim of the present study was to examine whether students' report card grades predict later school engagement. We hypothesized that higher report card grades predict higher levels of both emotional and behavioral engagement, even when controlling for levels of school engagement at the start of the school year (Hypothesis 1; Shim \& Ryan, 2005; You \& Sharkey, 2009).

The second aim of the study was to examine whether the presumed link between report card grades and school engagement is mediated by the positive and negative affective reactions that grades trigger. We predicted that higher report card grades will induce positive affective reactions, which in turn predict higher engagement (Hypothesis 2; Watson et al., 1999; Pekrun \& Linnenbrink-Garcia, 2012). Furthermore, we predicted that higher report card grades will reduce negative affective reactions, which in turn predict higher emotional engagement (Hypothesis 3; Pekrun et al., 2002). In light of the mixed findings and theorizing on the effects of negative affect on behavioral engagement (Pekrun \& Linnenbrink-Garcia, 2012; Watson et al. 1999), we did not formulate any directional hypotheses regarding this link.

The third aim of the study was to examine whether the presumed mediation of positive and negative affect will be moderated by students' perceptions of the performance norms in their classroom. We predicted that higher performance norms would strengthen the link between students' grades and their affective reactions. This stronger link, in turn, would result in larger indirect effects of grades on engagement via affective reactions (Hypothesis 4; i.e., moderated mediation, see Hayes, 2013; Preacher, Rucker, \& Hayes, 2007). Finally, we explored whether gender moderates the link between grades and affective reactions.

The present study extends past research in important ways. First, it contributes to the relatively recent field of research on emotional aspects of learning and achievement in educational contexts (Linnenbrink-Garcia \& Pekrun, 2011) by examining affective reactions to report card grades. Second, whereas school engagement has been typically examined as an antecedent of school performance, we now examine school engagement as a consequence of school performance. In doing so, we focus on a particularly meaningful phase in students' academic careers: their first semester in secondary school, a time marked by normative declines in school engagement (You \& Sharkey, 2009). Third, this study examines underlying mechanisms that can explain how report card grades are linked with school engagement. To our knowledge, this study is the first to test empirically how affective reactions mediate the link between grades and school engagement. Fourth, we examine performance norms - an important aspect of the peer context in which students receive their grades-as a putative moderator, 


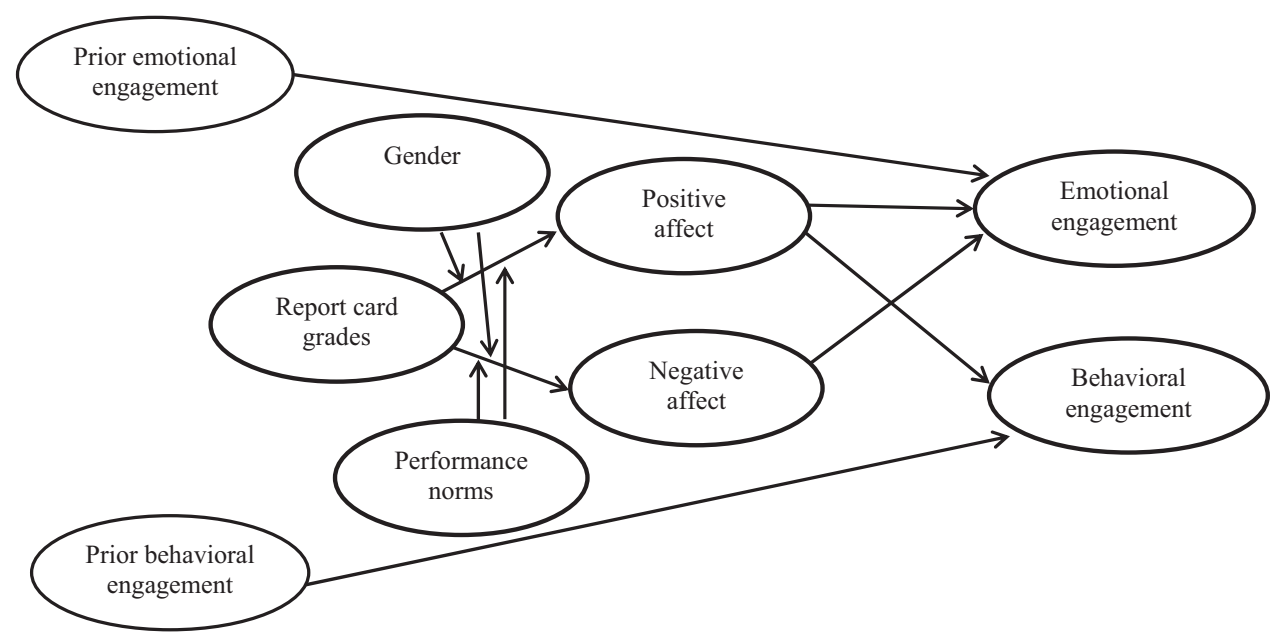

Figure 1. Conceptual model of the links between report card grades and school engagement via affective reactions, controlling for prior levels of engagement. The links between grades and affective reactions are predicted to be moderated by performance norms and gender.

thereby improving our understanding of peer influence on the psychological impact of grades.

\section{Method}

\section{Participants}

We conducted a three-wave longitudinal study among 438 Dutch seventh graders (53\% girls) recruited from 19 classrooms in three secondary schools. As is common in the Dutch school system, the students transitioned into secondary school between sixth and seventh grade.

Participants were 11 to 14 years old $\left(M_{\text {age }}=12.6, S D=0.4\right)$ at the start of the study. Most participants $(87 \%)$ were of Dutch origin, $3 \%$ of Moroccan origin, and $2 \%$ of Turkish origin; others $(8 \%)$ were mainly of mixed cultural/ethnic origin. Nationwide $80 \%$ of the inhabitants of the Netherlands are of Dutch origin, indicating that there was a slight overrepresentation of this group in our sample. Informed parental consent was obtained for all participants. Consent rates ranged from $73 \%$ to $100 \%$ across classrooms $\left(M_{\text {consent rate }}=84 \%\right)$.

\section{Procedure}

Surveys were administered in students' classes at three time points. We measured students' emotional and behavioral engagement at Time 1 (September, 2 to 3 weeks after the secondary school transition) and Time 3 (March). Students' affective reactions to their first report card and performance norms were measured at Time 2 (early in December, 2 to 3 weeks after they received their first report card).

\section{Measures}

Emotional and behavioral engagement (Time 1 and Time 3). School engagement was measured using the Engagement Versus Disaffection With Learning Scale (Skinner et al., 2008) both at the start of the school year (September) and 6 months later (March). This scale consists of four subscales (behavioral engagement, behavioral disaffection, emotional engagement, and emotional disaffection). We aggregated the positive and negative emotional subscales and the positive and negative behavioral subscales (engagement and disaffection) by reverse coding when appropriate. The resulting 10-item emotional engagement scale measured students' emotional involvement during learning activities (e.g., "I enjoy learning new things in class"; "When we work on something in class, I feel bored"). The 10-item behavioral engagement scale measured students' effort, attention, and persistence during classroom activities (e.g., "When I am in class, I listen very carefully"; "I don't try very hard in school"). Items were rated on a 4-point scale $(1=$ not at all true; $4=$ completely true $)$. Cronbach's alpha was .77 (Time 1) and .79 (Time 3) for behavioral engagement and .77 (Time 1) and .78 (Time 3) for emotional engagement.

Report card grades. Report card grades for six main academic subjects (i.e., Dutch, English, math, biology, history, and geography) were retrieved from school records. In the Dutch school system, grades range from 1 (extremely low) to 10 (extremely high). A grade below 5.5 is considered a failing grade. Cronbach's alpha was .75.

Affective reactions to report card grades (Time 2). Participants' affective reactions to their report card grades were measured using the Positive Affect and Negative Affect Schedule (Watson et al., 1988). The 10-item positive affect subscale captures positive, active and alert mood states (e.g., interested, attentive, proud). The 10-item negative affect subscale captures a range of activating aversive mood states (e.g., upset, ashamed, irritable). Participants were asked to rate on a 5-point scale $(1=$ very slightly or not at all; 5 = very $m u c h)$ to what extent they had experienced each mood state the moment they saw their report card for the first time. Cronbach's alpha was .94 for positive affect and .91 for negative affect. The correlation between both scales was significant $(r=-.29, p<.001)$, but moderate. 
Performance norms (Time 2). Performance norms were measured by asking participants to estimate the grades that each individual classmate received; a direct measure of how students expect others to perform. Ratings were given on a 5-point scale $(1=$ receives very low grades $; 5=$ receives very high grades $) . \mathrm{A}$ performance norm score was computed for each participant, by averaging the ratings he or she gave (number of ratings ranged from 19 to 31 across classrooms, $M_{\text {number of ratings }}=27$ ).

\section{Statistical Analyses}

We used structural equation modeling in Mplus 7.11 (Muthén \& Muthén, 1998-2012) to analyze our data. Emotional engagement, behavioral engagement, report card grades, positive affect, and negative affect were modeled as latent variables. As recommended by Little (2013, p. 24), for each latent variable, items were assigned to three parcels (i.e., packages of several items) using a balancing approach (i.e., assigning the item with the highest itemscale correlation to be paired with the item with the lowest itemscale correlation in Parcel 1, the items with the next highest and lowest item-scale correlation in Parcel 2, etc.). For emotional and behavioral engagement, the same parcels were used at Time 1 and Time 3 (item-scale correlations were averaged across time to create the ranking of the items). ${ }^{3}$ Performance norms constituted an observed variable. A latent variable with one indicator was created for this observed variable to facilitate latent variable interaction analyses and to take cases with missing data on performance norms into account (Muthén \& Muthén, 1998-2012). The residual variance of the indicator was fixed at a small value of 0.01 to overcome identification problems (Barendse, Oort, Werner, Ligtvoet, \& Schermelleh-Engel, 2012).

First, we examined the direct effect of report card grades on emotional and behavioral engagement. Second, positive and negative affective reactions to grades were considered as mediators of the link between grades and engagement. Third, we tested whether the mediation through positive and negative affect was moderated by performance norms and gender. In all models, we controlled for levels of emotional and behavioral engagement at the start of the school year. By modeling prior levels of engagement, change variance in engagement was isolated such that the predictive strength of grades and affective reactions on change in engagement could be examined (Little, 2013, p. 293). Importantly, this kind of modeling concerns rank-order (i.e., between-person) change, not intraindividual (i.e., within-person) change. This means that we examined individual differences in engagement in spring that were not present at baseline. The dependent variables were allowed to correlate.

Strict measurement invariance was found for emotional and behavioral engagement over time: differences between comparative fit indexes ( $\Delta$ CFIs) for the unconstrained model, the weak invariant model, the strong invariant model, and the strict invariant models were smaller than 0.01 (see Appendix; Cheung \& Rensvold, 2002). The measurement model including report card grades and emotional and behavioral engagement (Times 1 and 3) showed acceptable fit, $\chi^{2}(88, N=436)=170.3, \mathrm{CFI}=0.97$, root-meansquare error of approximation (RMSEA) $=.046,90 \%$ confidence interval (CI) for RMSEA [.036; .057]. The same was true for the measurement model to which positive and negative affect were added, $\chi^{2}(176, N=438)=373.29, \mathrm{CFI}=0.96, \mathrm{RMSEA}=.051$, 90\% CI for RMSEA [.043; .058].

Some data were missing at each measurement occasion: $3 \%$ at Time $1,7.5 \%$ at Time $2,3.5 \%$ at Time 3 , and $7 \%$ for grades. The percentage of missing data for each variable ranged between $3 \%$ and $7.5 \%$. Full information maximum likelihood was used to handle these missing values.

Because of the nested structure of the data (students in classrooms), we computed intraclass correlations (ICCs) to assess the degree to which students within classrooms are more similar to each other than children between classrooms. All ICCs were very low-i.e., 0.014 for negative affect, 0.008 for positive affect, 0.001 for emotional engagement (Time 3), and 0.000 for behavioral engagement (Time 3) -indicating that the effects of nestedness were very small. Because of the low ICCs, we analyzed all of the data together, collapsing across classrooms.

\section{Results}

\section{Preliminary Analyses}

Table 1 shows the descriptive statistics and correlations among the measured study variables. The average report card grade was 7.2 on a $1-10$ scale, which is equivalent to an $\mathrm{A}-/ \mathrm{B}+$ in the American school system (Netherlands Organisation for International Cooperation in Higher Education, 2011). As expected, report card grades were related to both positive and negative affective reactions to grades, and to emotional and behavioral engagement. Although emotional and behavioral engagement were relatively strongly correlated $(r=.61$ at Time 1 and $r=.68$ at Time 3), they did not perfectly overlap so it seemed justified to examine their affective correlates separately for conceptual reasons.

Analyses comparing boys' and girls' report card grades and affective reactions to grades revealed two gender differences. On average, girls obtained higher grades than boys, $t(420)=-3.44$, $p<.01, d=-0.34$. Also, girls experienced less negative affect in response to their grades than boys, $t(314.5)=2.75, p<.01, d=$ 0.27 , but there were no differences in positive affect, $t(418)=-1.04, p=.30$.

A 2 (Time) $\times 2$ (Gender) repeated measures analysis of variance (ANOVA) with emotional engagement as dependent variable showed that emotional engagement decreased over the course of the first year in secondary school, $F(1,407)=41.37, p<.001$. This main effect, however, was qualified by a Time $\times$ Gender interaction, showing that emotional engagement decreased more strongly for boys than for girls, $F(1,407)=6.86, p<.01$. A similar repeated-measures ANOVA showed that behavioral en-

\footnotetext{
${ }^{3}$ It has been argued that the use of parcels has several advantages over the use of items, including a higher reliability and a lower likelihood of distributional violations (Little, 2013; Little, Rhemtulla, Gibson, Schoemann, 2013). Parceling has recently also been criticized by Marsh, Lüdtke, Nagengast, Morin, and Von Davier (2013) because it can camouflage sources of misfit if the constructs are not unidimensional, which is especially problematic if the focus is on scale construction, latent means, measurement invariance, and differential item functioning. This was not the case in the present study. Furthermore, exploratory factor analyses showed that the constructs were relatively unidimensional with mean factor loadings ranging from .58 to .84 .
} 
Table 1

Means, Standard Deviations, and Intercorrelations for the Study Variables

\begin{tabular}{|c|c|c|c|c|c|c|c|c|c|}
\hline Variable & $M$ & $S D$ & 1 & 2 & 3 & 4 & 5 & 6 & 7 \\
\hline 1. Emotional engagement (T1) & 3.25 & 0.39 & - & & & & & & \\
\hline 2. Behavioral engagement (T1) & 3.19 & 0.41 & $.61^{* *}$ & - & & & & & \\
\hline 3. Mean report card grade & 7.16 & 0.75 & $.11^{*}$ & $.12 *$ & - & & & & \\
\hline 4. Positive affective reactions (T2) & 3.17 & 0.94 & $.28^{* *}$ & $.26^{* *}$ & $.49^{* *}$ & - & & & \\
\hline 5. Negative affective reactions (T2) & 1.44 & 0.61 & $-.17^{\text {*** }}$ & $-.15^{* *}$ & $-.49^{* *}$ & $-.29^{* *}$ & - & & \\
\hline 6. Performance norms (T2) & 3.23 & 0.32 & .08 & .00 & $-.13^{*}$ & .09 & $.11^{*}$ & - & \\
\hline 7. Emotional engagement (T3) & 3.12 & 0.40 & $.50^{* * *}$ & $.38^{* * *}$ & $.23^{* *}$ & $.34^{* * *}$ & $-.31^{* * *}$ & .09 & - \\
\hline 8. Behavioral engagement (T3) & 3.03 & 0.44 & $.40^{\text {*** }}$ & $.60^{* *}$ & $.19^{\text {** }}$ & $.32^{* *}$ & $-.17^{* *}$ & .05 & $.68^{* *}$ \\
\hline
\end{tabular}

Note. $\mathrm{T} 1=$ Time $1 ; \mathrm{T} 2=$ Time $2 ; \mathrm{T} 3=$ Time 3

${ }^{*} p<.05 . \quad{ }^{* * *} p<.001$.

gagement also decreased over time, $F(1,407)=68.74, p<.001$. No gender differences were found for behavioral engagement $(p s>.20)$.

\section{Grades Predicting School Engagement}

First, we examined whether report card grades predict emotional and behavioral engagement at Time 3 (spring), when controlling for levels of emotional and behavioral engagement at Time 1 (fall). All variables were modeled as latent constructs. Overall, the model demonstrated acceptable fit, $\chi^{2}(88, N=436)=170.4$, CFI $=$ 0.969, RMSEA $=.046,90 \%$ CI for RMSEA [.036; .057].

Emotional engagement in spring was predicted by initial level of emotional engagement, $b=0.51, \beta=.51, S E=.12, p<.001$, but not by initial levels of behavioral engagement, $b=0.06, \beta=.06$, $S E=.12, p=.60$. Similarly, behavioral engagement in spring was predicted by initial levels of behavioral engagement, $b=0.87$, $\beta=.79, S E=.12, p<.001$, but not by initial levels of emotional engagement, $b=-0.16, \beta=-.15, S E=.12, p=.17$. More important, report card grades predicted both emotional engagement and behavioral engagement above and beyond prior levels of engagement, $b=0.19, \beta=.19, S E=.06 p<.001$ and $b=0.15$, $\beta=.13, S E=.06, p<.05$, respectively. Thus, consistent with Hypothesis 1, higher grades predicted increased emotional and behavioral engagement over the course of the first school year.

\section{Mediation Analyses}

Next, it was examined whether positive and negative affective reactions mediated the link between report card grades and school engagement (see Figure 2 and Table 2). Because of the affective nature of both emotional engagement and affective reactions, emotional engagement at Time 1 was included as a predictor of positive and negative affect. The final model demonstrated acceptable fit, $\chi^{2}(179, N=438)=375.6, \mathrm{CFI}=0.963, \mathrm{RMSEA}=.050$, $90 \%$ CI for RMSEA [.043; .057].

Bootstrapping procedures were used to examine whether the indirect effects through positive and negative affect were significant (see Preacher \& Hayes, 2008). In bootstrapping, a large number of bootstrap samples (in the present analyses, $B=5,000$ ) are generated from the original data set. For each bootstrap sample, the indirect effects (i.e., mediated effects) of report card grades on engagement through positive and negative affective reactions were computed. The distribution of these indirect effects was then used

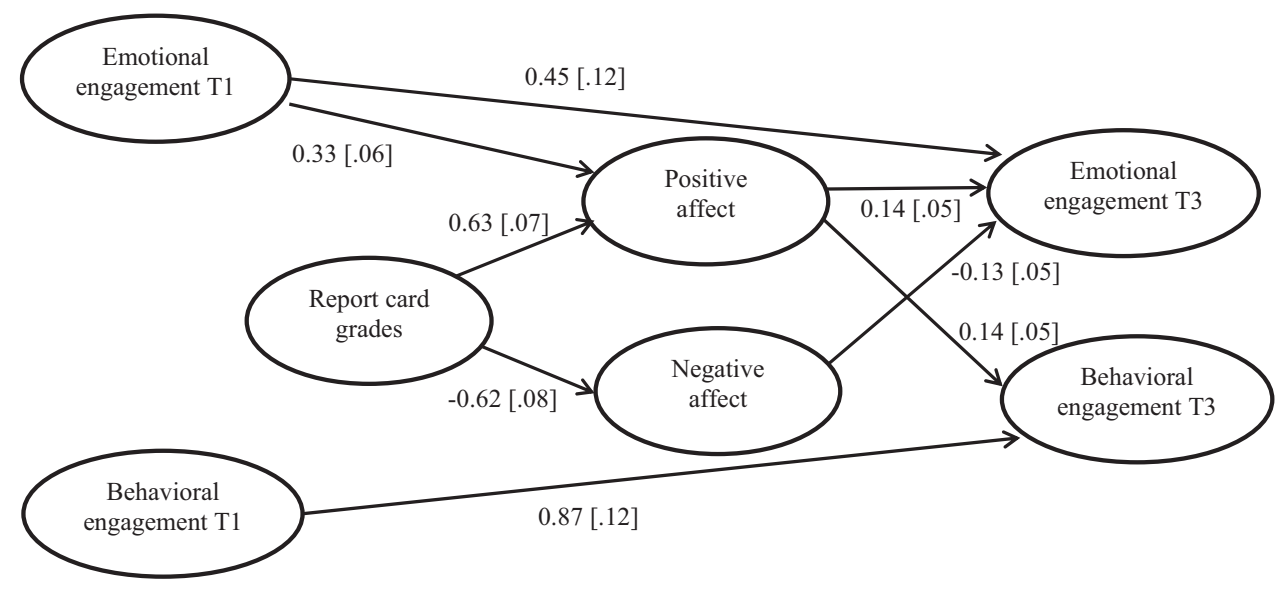

Figure 2. Path model for the effect of report card grades on emotional and behavioral engagement (Time 3) through positive and negative affect, controlled for prior levels of emotional and behavioral engagement (Time 1). Unstandardized coefficients are reported. Standard errors are in brackets. Only statistically significant path coefficients are shown (for all path coefficients, see Table 2). Dependent variables are allowed to correlate. 
Table 2

Path Coefficients for the Effect of Report Card Grades on Emotional and Behavioral Engagement (Time 3) Through Positive and Negative Affect (Time 2), Controlled for Prior Levels of Emotional and Behavioral Engagement (Time 1)

\begin{tabular}{|c|c|c|c|}
\hline Variable & $b$ & $\beta$ & $S E$ \\
\hline Report card grades $\rightarrow$ Negative affect & $-0.62^{* * * *}$ & -.52 & .08 \\
\hline Emotional engagement (T1) $\rightarrow$ Negative affect & -0.12 & -.10 & .06 \\
\hline Report card grades $\rightarrow$ Positive affect & $0.63^{* * * *}$ & .51 & .07 \\
\hline Emotional engagement $(\mathrm{T} 1) \rightarrow$ Positive affect & $0.33^{* * * *}$ & .27 & .06 \\
\hline Report card grades $\rightarrow$ Emotional engagement (T3) & 0.02 & .02 & .08 \\
\hline Positive affect $\rightarrow$ Emotional engagement (T3) & $0.14^{*}$ & .18 & .05 \\
\hline Negative affect $\rightarrow$ Emotional engagement (T3) & $-0.13^{*}$ & -.15 & .05 \\
\hline Behavioral engagement (T1) $\rightarrow$ Emotional engagement (T3) & 0.06 & .06 & .11 \\
\hline Emotional engagement (T1) $\rightarrow$ Emotional engagement (T3) & $0.45^{\text {**** }}$ & .45 & .12 \\
\hline Report card grades $\rightarrow$ Behavioral engagement (T3) & 0.05 & .04 & .09 \\
\hline Positive affect $\rightarrow$ Behavioral engagement (T3) & $0.14^{* *}$ & .16 & .05 \\
\hline Negative affect $\rightarrow$ Behavioral engagement (T3) & -0.01 & -.01 & .05 \\
\hline Behavioral engagement (T1) $\rightarrow$ Behavioral engagement (T3) & $0.87^{* * * *}$ & .79 & .12 \\
\hline Emotional engagement (T1) $\rightarrow$ Behavioral engagement (T3) & -0.21 & -.19 & .12 \\
\hline
\end{tabular}

Note. $\mathrm{T} 1=$ Time $1 ; \mathrm{T} 3=$ Time 3

${ }^{*} p<.05 .{ }^{* *} p<.01 .{ }^{* * *} p<.001$.

to obtain $95 \%$ confidence intervals for the size of the indirect effects for both positive and negative affect.

The indirect effects of report card grades via positive affect on both emotional engagement and behavioral engagement were significant (see Table 3). These findings confirm Hypothesis 2, showing that higher report card grades predicted higher positive affect, which subsequently predicted higher emotional and behavioral engagement. Furthermore, confirming Hypothesis 3, the indirect effect of report card grades via negative affect was significant for the outcome of emotional engagement. For the outcome of behavioral engagement, the effect was not significant (see Table 3). Thus, higher report card grades predicted lower negative affect, which subsequently predicted higher emotional engagement, but not behavioral engagement. When positive and negative affect were included in the model, the direct effects of grades on emotional and behavioral engagement became nonsignificant, suggesting full mediation.

\section{Moderated Mediation}

Next, it was tested whether the links between grades and affective reactions were moderated by performance norms and gender, by including latent interaction terms in the model (Klein \& Moosbrugger, 2000; Muthén \& Muthén, 1998-2012). As recommended by Little (2013, p. 321), initially, gender and performance norms were tested as moderators of the link between grades and affective reactions in separate models. Next, all significant interaction effects were included in one model.

First, performance norms and the Report Card Grades $\times$ Performance Norms interaction were added to the model as predictors of negative affect and positive affect. Performance norms predicted neither negative affect, nor positive affect, $b=0.86, S E=$ $1.03, p=.40$ and $b=-0.52, S E=1.46, p=.72$, respectively. Consistent with Hypothesis 4 , the Report Card Grades $\times$ Performance Norms interaction significantly predicted negative affect, $b=-1.26, S E=0.48, p<.01$. A similar effect was, however, not found for positive affect, $b=0.02, S E=0.19, p=.93$. Simple slope analyses showed that the link between grades and negative affect was stronger for students who perceived performance norms in their class to be high (i.e., $1 S D$ above the mean), than for students who perceived performance norms in their class to be low (i.e., $1 S D$ below the mean), $b=-0.93, S E=0.24, p<.001$ and $b=-0.22, S E=0.14, p=.14$, respectively.

Table 3

Effect of Report Card Grades on Behavioral and Emotional Engagement at Time 3 Through Positive and Negative Affect, Controlled for Engagement at Time 1

\begin{tabular}{lrr}
\hline Variable & Unstandardized effect & $\begin{array}{c}\text { Boot } 95 \% \\
\text { confidence interval }^{\mathrm{a}}\end{array}$ \\
\hline Grades $\rightarrow$ Positive affect $\rightarrow$ Emotional engagement & $.09^{*}$ & .02 to .18 \\
Grades $\rightarrow$ Positive affect $\rightarrow$ Behavioral engagement & $.09^{*}$ & .01 to .18 \\
Grades $\rightarrow$ Negative affect $\rightarrow$ Emotional engagement & $.08^{*}$ & .02 to .16 \\
Grades $\rightarrow$ Negative affect $\rightarrow$ Behavioral engagement & .00 & -.07 to .07 \\
Grades $\rightarrow$ Emotional engagement & .02 & -.17 to .20 \\
Grades $\rightarrow$ Behavioral engagement & .05 & -.15 to .24 \\
\hline
\end{tabular}

${ }^{\text {a }}$ Bootstrap $95 \%$ confidence intervals are bias-corrected.

$* p<.05$. 
Second, to explore gender differences, gender and the Report Card Grades $\times$ Gender interaction were added to the model as predictors of negative affect and positive affect. Gender predicted neither negative affect, nor positive affect, $b=-0.11, S E=0.11$, $p=.31$ and $b=-0.11, S E=0.11, p=.33$. The Report Card Grades $\times$ Gender interaction significantly predicted negative affect, but not positive affect, $b=0.61, S E=0.21, p<.01$ and $b=-0.03, S E=0.12, p=.83$, respectively. Simple slopes analyses showed that the link between grades and negative affect was stronger for boys than for girls, $b=-1.00, S E=0.19, p<$ .001 and $b=-0.39, S E=.08, p<.001$,

Finally, a model was examined in which both interactions (Report Card Grades $\times$ Performance Norms and Report Card Grades $\times$ Gender) were included as predictors of negative affect. The main effects of performance norms and gender were also included as predictors of negative affect. Both interactions remained significant. See Figure 3 and Table 4 for the path coefficients of this final model.

To explore the effect of the moderators on the indirect effect of grades via negative affect on engagement (i.e., moderated mediation), the indirect effects were probed in a way analogous to standard moderation analyses. Using the moderator centering approach (Preacher et al., 2007), we computed the indirect effects of negative affect on emotional and behavioral engagement at two different levels of performance norms (i.e., $1 S D$ below the mean and $1 S D$ above the mean) and for boys and girls separately (see Table 5). Because bootstrapping is not available in Mplus when estimating latent interactions, normal $95 \%$ confidence intervals are reported.

Consistent with Hypothesis 4, the indirect effect of grades via negative affect on emotional engagement was stronger to the extent that students perceived performance norms in their class to be high. Also, this indirect effect of negative affect was stronger for boys than for girls, showing that boys reacted with stronger negative affect to their grades than girls. The indirect effect of grades via negative affect on behavioral engagement was not significant for any level of performance norms, neither for boy nor for girls. These analyses support the mediation analyses above, showing that the effect of report card grades on behavioral engagement is not mediated by negative affective reactions to those grades at any level of performance norms.

\section{Discussion}

This study contributes to the literature on school engagement by elucidating the affective processes that help account for the effects of grades on engagement in a new school environment. Not only do the current findings replicate prior findings regarding declines in engagement after transitioning to secondary school (Eccles et al., 1993; Fredricks \& Eccles, 2002), they also help us understand why some youth become behaviorally and emotionally disengaged. We showed that higher grades predicted increased emotional and behavioral engagement over time. Thus, the results of this study suggest that it is important to consider engagement as a response to performance feedback, not only as an antecedent of school performance (Fredricks et al., 2004; You \& Sharkey, 2009). As far as we know, this study is the first to test mediation between grades and school engagement by examining affective reactions to report card grades.

The current study was designed to examine the ways in which the very first report card grades in secondary school shape students' school engagement during their first year in secondary school. Higher grades predicted increased emotional and behavioral engagement over time. Moreover, students' affective reac-

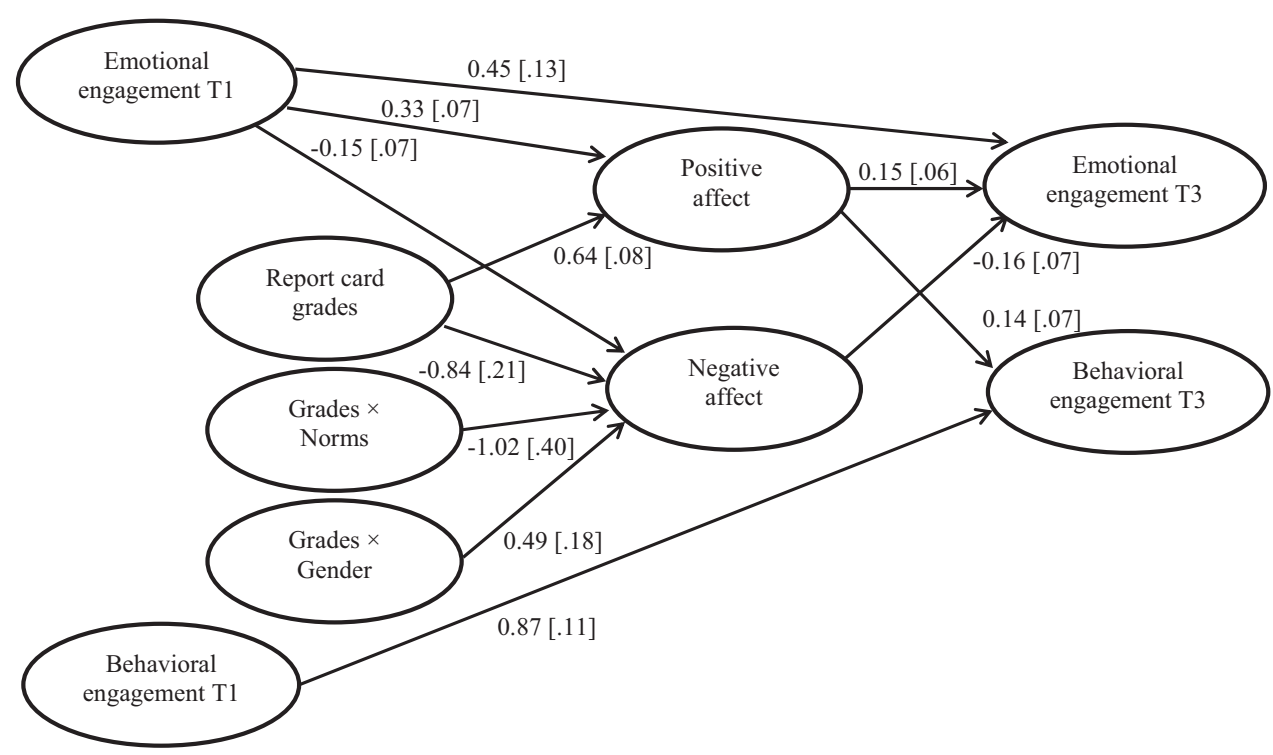

Figure 3. Path model for the effect of report card grades on emotional and behavioral engagement (Time 3) through positive and negative affect, controlled for prior levels of emotional and behavioral engagement (Time 1), moderated by performance norms and gender. Unstandardized coefficients are reported. Standard errors are in brackets. Only statistically significant path coefficients are shown (for all path coefficients, see Table 4). 
Table 4

Path Coefficients for the Effect of Report Card Grades on Emotional and Behavioral Engagement (Time 3) Through Positive and Negative Affect (Time 2), Controlled for Prior Levels of Emotional and Behavioral Engagement (Time 1), Moderated by Performance Norms and Gender

\begin{tabular}{|c|c|c|}
\hline Variable & $b$ & $S E$ \\
\hline Report card grades $\rightarrow$ Negative affect & $-0.84^{* * * *}$ & .21 \\
\hline Performance norms $\rightarrow$ Negative affect & 1.37 & .86 \\
\hline Gender $\rightarrow$ Negative affect & -0.13 & .11 \\
\hline Grades $\times$ Performance norms $\rightarrow$ Negative affect & $-1.02^{*}$ & .40 \\
\hline Grades $\times$ Gender $\rightarrow$ Negative affect & $0.49^{* *}$ & .18 \\
\hline Emotional engagement (T1) $\rightarrow$ Negative affect & $-0.15^{*}$ & .07 \\
\hline Report card grades $\rightarrow$ Positive affect & $0.64^{* * * *}$ & .08 \\
\hline Emotional engagement $(\mathrm{T} 1) \rightarrow$ Positive affect & $0.33^{* * * *}$ & .07 \\
\hline Report card grades $\rightarrow$ Emotional engagement (T3) & -0.02 & .10 \\
\hline Positive affect $\rightarrow$ Emotional engagement (T3) & $0.15^{* * * *}$ & .06 \\
\hline Negative affect $\rightarrow$ Emotional engagement (T3) & $-0.16^{* * * *}$ & .07 \\
\hline Behavioral engagement (T1) $\rightarrow$ Emotional engagement (T3) & 0.06 & .12 \\
\hline Emotional engagement (T1) $\rightarrow$ Emotional engagement (T3) & $0.45^{* * *}$ & .13 \\
\hline Report card grades $\rightarrow$ Behavioral engagement (T3) & 0.05 & .10 \\
\hline Positive affect $\rightarrow$ Behavioral engagement (T3) & $0.14^{*}$ & .07 \\
\hline Negative affect $\rightarrow$ Behavioral engagement (T3) & -0.02 & .06 \\
\hline Behavioral engagement $(\mathrm{T} 1) \rightarrow$ Behavioral engagement $(\mathrm{T} 3)$ & $0.87^{* * * *}$ & .11 \\
\hline Emotional engagement (T1) $\rightarrow$ Behavioral engagement (T3) & -0.21 & .12 \\
\hline
\end{tabular}

Note. $\mathrm{T} 1=$ Time $1 ; \mathrm{T} 3=$ Time 3

${ }^{*} p<.05 . \quad{ }^{* * *} p<.01 .{ }^{* * * *} p<.001$.

tions to their grades mediated these effects, albeit in different ways for emotional and behavioral engagement. Whereas the link between grades and emotional engagement was mediated by both positive and negative affective processes, the link between grades and behavioral engagement was exclusively mediated by positive affect. Thus, students may come to act passively in the classroom, not so much because they experience strong negative feelings (e.g., distress, shame, anxiety), but rather because they experience reduced positive feelings (e.g., activation, inspiration, excitement).

An alternative explanation for the nonsignificant link between negative affect and behavioral engagement is that two countervailing effects may be working simultaneously: Prior research shows that activating negative emotions has detrimental effects on behavioral engagement for some individuals but positive effects for others (e.g., Martin, 2011; Turner \& Schallert, 2001). Pekrun et al. (2002, 2011) argued that whereas deactivating or inhibiting negative emotions (e.g., hopelessness or boredom) have universal detrimental effects on students' engagement, activating negative emotions can have variable effects on students' engagement because they elicit mixed motivational responses. Empirically, they found that anxiety and shame were linked to decreased intrinsic motivation (i.e., motivation to learn because the learning is enjoyable) but increased extrinsic motivation (i.e., motivation to learn to attain outcomes such as high grades; Pekrun et al., 2011). The joint effects of these different motivational responses may determine whether students who experience negative affective reactions to their grades will invest increased effort to avoid future failure or instead disengage from their school work. Thus, it may well be that these two competing motivational forces that both stem from negative affect may have increased engagement in some students but decreased engagement in others, thus canceling out a main effect in our analyses.

Affective reactions and their possible effects on engagement do not take place in a social vacuum, however. We found that the link

Table 5

Indirect Effects of Report Card Grades on Emotional and Behavioral Engagement (Time 3) Through Negative Affect at Different Levels of Performance Norms, Controlled for Engagement at Time 1

\begin{tabular}{|c|c|c|c|c|}
\hline Variable & $\begin{array}{l}\text { Indirect } \\
\text { effect boys }\end{array}$ & $\begin{array}{l}95 \% \text { confidence } \\
\text { interval }\end{array}$ & $\begin{array}{l}\text { Indirect } \\
\text { effect girls }\end{array}$ & $\begin{array}{l}95 \% \text { confidence } \\
\text { interval }\end{array}$ \\
\hline \multicolumn{5}{|c|}{ Grades $\rightarrow$ Negative affect $\rightarrow$ Emotional engagement } \\
\hline Low performance norms & $0.09^{*}$ & 0.002 to 0.17 & 0.01 & -0.04 to 0.06 \\
\hline High performance norms & $0.18^{*}$ & 0.03 to 0.34 & $0.11^{*}$ & 0.01 to 0.20 \\
\hline \multicolumn{5}{|c|}{ Grades $\rightarrow$ Negative affect $\rightarrow$ Behavioral engagement } \\
\hline Low performance norms & 0.01 & -0.05 to 0.07 & 0.00 & -0.01 to 0.01 \\
\hline High performance norms & 0.02 & -0.11 to 0.16 & 0.01 & -0.06 to 0.09 \\
\hline
\end{tabular}

Note. Low performance norms are one $S D$ below the mean. High performance norms are one $S D$ above the mean. Indirect effects are based on unstandardized coefficients.

${ }^{*} p<.05$. 
between grades, negative affect, and subsequent emotional school engagement was stronger for students who perceived their classmates to obtain high grades. Students perceiving high performance norms experienced relatively high levels of negative affect when faced with low grades, and relatively low levels of negative affect when faced with high grades. Students are likely to compare their grades to the grades of their classmates (Pulfrey et al., 2011; Trautwein et al., 2006). Adolescents who feel that the classroom norms for performance are high may come to attach more importance to their own performance, resulting in stronger negative affective reactivity to their report card.

We also explored and found gender differences highlighting the role of negative affective reactions among boys. Boys' negative affective reactivity to grades was stronger than girls', which resulted in stronger effects of grades on boys' emotional engagement via negative affect. Although in many situations boys are somewhat less emotionally reactive than girls (e.g., Charbonneau et al., 2009; Rudolph, 2002), our results suggest this is not the case in the specific context of receiving grades. Grades encourage social comparison and highlight students' normative standing in the peer group (Pulfrey et al., 2011). It may be the competitive nature of grades that makes boys more reactive to them (e.g., Hibbard \& Buhrmester, 2010). Because adolescent boys on average obtain lower grades than girls (e.g., Lam et al., 2012) and experience relatively strong negative affect in response to those grades, they are especially vulnerable to declines in emotional engagement.

The strengths of the present study include the measurement of school engagement at different time points. This allowed testing of the effects of grades and students' affective reactions on school engagement, while controlling for prior levels of school engagement, thus providing insight in whether grades and affective reactions can predict changes in engagement over and above rank order stability. Furthermore, the study was designed to test these effects at a critical time period: shortly after the secondary school transition, when many students show a decline in school engagement (Eccles et al., 1993). Finally, we considered the larger social context in which students react to their grades by examining perceptions of classmates' grades. Rather than asking students what the typical grades are among their classmates, we obtained a more informed measure by relying on aggregates of how students' believe each of their classmates perform. In spite of these strengths, a number of limitations should be noted.

First, we assessed the rather broad dimensions of positive and negative affect, not discrete emotions (e.g., shame, anxiety, guilt, and anger). It is possible that discrete negative emotions lead to different patterns of engagement (Pekrun et al., 2011). For example, guilt is theorized to arise in response to controllable causes of failure and to increase engagement (Weiner, 1985, 2010). In contrast, shame is theorized to arise in response to uncontrollable causes of failure and to induce decreases in engagement (Weiner, 1985, 2010). Although in our sample shame and guilt were strongly correlated $(r=.73)$, future research might benefit from assessing discrete achievement emotions and examining their differential effects on engagement (e.g., see Pekrun et al., 2011).

Second, we chose to focus on affective reactions as a mediating mechanism. Of course, this is not to say that other mediating mechanisms are unimportant. For example, low grades also induce lower expectancies of subsequent performance, which have been shown to be related to lower persistence and interest (e.g., Denis- sen et al., 2007; Wigfield \& Eccles, 2000; Wigfield, Tonks, \& Klauda, 2009). Future research could test various putative mediating mechanisms in the same study to compare their relative strength.

Third, we measured report card grades, which provide an overall summery of students' performance in the preceding period. Receiving a report card is a highly salient event for many students and their parents, in part because academic decisions (e.g., retaining a grade) are based on these grades. Still, students already receive performance feedback on exams and assignments prior to their report card, which potentially affects their school engagement even earlier in the school year. Future research is needed to establish whether report card grades or grades and performance feedback on individual assignments and exams may be more important for changes in school engagement.

Fourth, consistent with most other studies on school engagement, we measured behavioral and emotional engagement as general constructs and did not differentiate between school subjects (for a review on engagement measures, see Fredricks \& McColskey, 2012). Assessing school engagement separately for different subjects may be an important direction for future research to determine to what extent children's emotional and behavioral engagement are domain-specific and to what extent they represent a general tendency (e.g., Eccles \& Wang, 2012; Fredricks \& McColskey, 2012).

Fifth, although the intervals between the measurement occasions in our study were relatively short when compared to most longitudinal studies (i.e., 3-monthly, rather than half-yearly or yearly), a longitudinal design with even shorter time intervals might have permitted us to capture the change processes in more detail (Collins, 2006). Theoretically, an immediate effect of students' affective reactions to grades on their levels of school engagement may be expected (Pekrun, 2006). We measured school engagement 3 months later-a period during which other events influencing engagement may have occurred. Future research using more intensive repeated measure designs, such as experience sampling designs (Bolger, Davis, \& Rafaeli, 2003) is needed to test fine-grained changes in engagement in response to obtaining grades. In addition, future research could benefit from using a full longitudinal design measuring grades, affect, and engagement at each time point. Such a design takes the stability of each of these construct into account and provides more insight in the causal ordering of the processes than the current design (Mitchell \& Maxwell, 2013).

\section{Conclusions}

In many schools, giving grades is a daily routine, yet teachers may not always be fully aware of the possible emotional and behavioral consequences of the grades they provide. This study suggests that low grades may set in motion a downward spiral, whereby consequent declines in engagement result in even lower grades. Low-performing students who perceive their classmates to receive high grades are particularly vulnerable. Also, boys are vulnerable for declines in engagement because they tend to receive lower grades and are more affectively reactive to grades than girls. We do not suggest that the common practice to evaluate schoolwork with grades should be abandoned. Grades can provide vital information to teachers, students, and parents and can be used to enhance both teaching and learning (Guskey \& Bailey, 2001). Additionally, students who perform well at 
the start of secondary school are likely to be more involved in their schoolwork during the school year. However, teachers should be aware of the potential negative consequences of the grades they give and try to reduce these. For example, prior research suggests that negative effects of grades may be prevented when teachers convey the message to their low-performing students that their difficulties are likely to be temporary and that when they exert more effort and use the right strategies they will be able to perform better (e.g., Robertson, 2000; Yeager \& Walton, 2011). Making a good start after the school transition may be vital for success in secondary school.

\section{References}

Alexander, K. L., Entwisle, D. R., \& Horsey, C. S. (1997). From first grade forward: Early foundations of high school dropout. Sociology of Education, 70, 87-107. doi:10.2307/2673158

Bandura, A. (1977). Self-efficacy: Toward a unifying theory of behavioral change. Psychological Review, 84, 191-215. doi:10.1037/0033-295X.84 2.191

Barber, B. K., \& Olsen, J. A. (2004). Assessing the transitions to middle and high school. Journal of Adolescent Research, 19, 3-30. doi:10.1177/ 0743558403258113

Barendse, M. T., Oort, F. J., Werner, C. S., Ligtvoet, R., \& SchermellehEngel, K. (2012). Measurement bias detection through factor analysis. Structural Equation Modeling, 19, 561-579. doi:10.1080/10705511 .2012 .713261

Bolger, N., Davis, A., \& Rafaeli, E. (2003). Diary methods: Capturing life as it is lived. Annual Review of Psychology, 54, 579-616. doi:10.1146/ annurev.psych.54.101601.145030

Butler, R. (1988). Enhancing and undermining intrinsic motivation: The effects of task-involving and ego-involving evaluation on interest and performance. British Journal of Educational Psychology, 58, 1-14. doi:10.1111/j.2044-8279.1988.tb00874.x

Charbonneau, A. M., Mezulis, A. H., \& Hyde, J. S. (2009). Stress and emotional reactivity as explanations for gender differences in adolescents' depressive symptoms. Journal of Youth and Adolescence, 38, 1050-1058. doi:10.1007/s10964-009-9398-8

Cheung, G. W., \& Rensvold, R. B. (2002). Evaluating goodness-of-fit indexes for testing measurement invariance. Structural Equation Modeling, 9, 233-255. doi:10.1207/S15328007SEM0902 5

Collins, L. M. (2006). Analysis of longitudinal data: The integration of theoretical model, temporal design, and statistical model. Annual Review of Psychology, 57, 505-528. doi:10.1146/annurev.psych.57.102904 190146

Connell, J. P., Spencer, M. B., \& Aber, J. A. (1994). Educational risk and resilience in African-American youth: Context, self, action, and outcomes in school. Child Development, 65, 493-506. doi:10.2307/ 1131398

Crocker, J., Karpinski, A., Quinn, D. M., \& Chase, S. K. (2003). When grades determine self-worth: Consequences of contingent self-worth for male and female engineering and psychology majors. Journal of Personality and Social Psychology, 85, 507-516. doi:10.1037/0022-3514 .85.3.507

Denissen, J. J. A., Zarrett, N. R., \& Eccles, J. S. (2007). I like to do it, I'm able, and I know I am: Longitudinal couplings between domain-specific achievement, self-concept, and interest. Child Development, 78, 430447. doi:10.1111/j.1467-8624.2007.01007.x

Dettmers, S., Trautwein, U., Lüdtke, O., Goetz, T., Frenzel, A. C., \& Pekrun, R. (2011). Students' emotions during homework in mathematics: Testing a theoretical model of antecedents and achievement outcomes. Contemporary Educational Psychology, 36, 25-35. doi:10.1016/ j.cedpsych.2010.10.001
Duckworth, A. L., \& Seligman, M. E. P. (2006). Self-discipline gives girls the edge: Gender in self-discipline, grades, and achievement test scores. Journal of Educational Psychology, 98, 198-208. doi:10.1037/00220663.98.1.198

Eccles, J. S., Midgley, C., Wigfield, A., Buchanan, C. M., Reuman, D., Flanagan, C., \& Mac Iver, D. (1993). Development during adolescence: The impact of stage environment fit on young adolescents' experiences in schools and in families. American Psychologist, 48, 90-101. doi: 10.1037/0003-066X.48.2.90

Eccles, J., \& Wang, M.-T. (2012). Part I commentary: So what is student engagement anyway? In S. L. Christenson, A. L. Reschly, \& C. Wylie (Eds.), Handbook of research on student engagement (pp. 133-145). New York, NY: Springer. doi:10.1007/978-1-4614-2018-7_6

Efklides, A., \& Petkaki, C. (2005). Effects of mood on students' metacognitive experiences. Learning and Instruction, 15, 415-431. doi:10.1016/ j.learninstruc.2005.07.010

Eysenck, M. W., Derakshan, N., Santos, R., \& Calvo, M. G. (2007), Anxiety and cognitive performance: Attentional control theory. Emotion, 7, 336-353. doi:10.1037/1528-3542.7.2.336

Fredricks, J. A., Blumenfeld, P. C., \& Paris, A. H. (2004). School engagement: Potential of the concept, state of the evidence. Review of Educational Research, 74, 59-109. doi:10.3102/00346543074001059

Fredricks, J. A., \& Eccles, J. S. (2002). Children's competence and value beliefs from childhood through adolescence: Growth trajectories in two male-sex-typed domains. Developmental Psychology, 38, 519-533. doi: 10.1037/0012-1649.38.4.519

Fredricks, J. A., \& McColskey, W. (2012). The measurement of student engagement. A comparative analysis of various methods and student self-report instruments. In S. L. Christenson, A. L. Reschly, \& C. Wylie (Eds.), Handbook of research on student engagement (pp. 763-782). New York, NY: Springer. doi:10.1007/978-1-4614-2018-7_37

Gneezy, U., \& Rustichini, A. (2004). Gender and competition at a young age. American Economic Review, 94, 377-381. doi:10.1257/ 0002828041301821

Goldstein, M. D., \& Strube, M. J. (1994). Independence revisited: The relation between positive and negative affect in a naturalistic setting. Personality and Social Psychology Bulletin, 20, 57-64. doi:10.1177/ 0146167294201005

Guskey, T. R., \& Bailey, J. M. (2001). Developing grading and reporting systems for student learning. Thousand Oaks, CA: Corwin Press.

Harter, S., Whitesell, N. R., \& Kowalski, P. (1992). Individual differences in the effects of educational transitions on young adolescent's perceptions of competence and motivational orientation. American Educational Research Journal, 29, 777-807. doi:10.3102/00028312029004777

Hayes, A. F. (2013). Introduction to mediation, moderation, and conditional process analysis. A regression-based approach. New York, NY: Guilford Press.

Hendriks, A. A. J., Kuyper, H., Lubbers, M. J., \& Van der Werf, M. P. C. (2011). Personality as a moderator of context effects on academic achievement. Journal of School Psychology, 49, 217-248. doi:10.1016/ j.jsp.2010.12.001

Hibbard, D. R., \& Buhrmester, D. (2010). Competitiveness, gender, and adjustment among adolescents. Sex Roles, 63, 412-424. doi:10.1007/ s11199-010-9809-Z

Klein, A., \& Moosbrugger, H. (2000). Maximum likelihood estimation of latent interaction effects with the LMS method. Psychometrika, 65, 457-474. doi:10.1007/BF02296338

Kluger, A. N., \& DeNisi, A. (1996). The effects of feedback interventions on performance: A historical review, a meta-analysis, and a preliminary feedback intervention theory. Psychological Bulletin, 119, 254-284. doi:10.1037/0033-2909.119.2.254

Kohn, A. (1994). Grading: The issue is not how but why. Educational Leadership, 52, 38-41. 
Lam, S., Jimerson, S., Kikas, E., Cefai, C., Veiga, F. H., Nelson, B., . . Zollneritsch, J. (2012). Do girls and boys perceive themselves as equally engaged in school? The results of an international study from 12 countries. Journal of School Psychology, 50, 77-94. doi:10.1016/j.jsp.2011 .07 .004

Li, Y., \& Lerner, R. M. (2011). Trajectories of school engagement during adolescence: Implications for grades, depression, delinquency, and substance use. Developmental Psychology, 47, 233-247. doi:10.1037/ a0021307

Linnenbrink-Garcia, L., \& Pekrun, R. (2011). Students' emotions and academic engagement: Introduction to the special issue. Contemporary Educational Psychology, 36, 1-3. doi:10.1016/j.cedpsych.2010.11.004

Linnenbrink-Garcia, L., Rogat, T. K., \& Koskey, K. L. K. (2011). Affect and engagement during small group instruction. Contemporary Educational Psychology, 36, 13-24. doi:10.1016/j.cedpsych.2010.09.001

Little, T. D. (2013). Longitudinal structural equation modeling. New York, NY: The Guilford Press.

Little, T. D., Rhemtulla, M., Gibson, K., \& Schoemann, A. M. (2013). Why the items versus parcels controversy needn't be one. Psychological Methods, 18, 285-300. doi:10.1037/a0033266

Marks, H. M. (2000). Student engagement in instructional activity: Patterns in the elementary, middle, and high school years. American Educational Research Journal, 37, 153-184. doi:10.3102/00028312037001153

Marsh, H. W., Lüdtke, O., Nagengast, B., Morin, A. J. S., \& Von Davier, M. (2013). Why item parcels are (almost) never appropriate: Two wrongs do not make a right: Camouflaging misspecification with item parcels in CFA models. Psychological Methods, 18, 257-284. doi: 10.1037/a0032773

Martin, A. J. (2011). Courage in the classroom: Exploring a new framework predicting academic performance and engagement. School Psychology Quarterly, 26, 145-160. doi:10.1037/a0023020

Masten, C. L., Juvonen, J., \& Spatzier, A. (2009). Relative importance of parents and peers. The Journal of Early Adolescence, 29, 773-799. doi: $10.1177 / 0272431608325504$

Maulana, R., Opdenakker, M., Stroet, K., \& Bosker, R. (2012). Observed lesson structure during the first year of secondary education: Exploration of change and link with academic engagement. Teaching and Teacher Education, 28, 835-850. doi:10.1016/j.tate.2012.03.005

Mitchell, M., \& Maxwell, S. E. (2013). A comparison of the cross-sectional and sequential designs when assessing longitudinal mediation. Multivariate Behavioral Research, 48, 301-339. doi:10.1080/00273171.2013 .784696

Molloy, L. E., Gest, S. D., \& Rulison, K. L. (2011). Peer influences on academic motivation: Exploring multiple methods of assessing youths' most "influential" peer relationships. The Journal of Early Adolescence, 31, 13-40. doi:10.1177/0272431610384487

Muthén, L. K., \& Muthén, B. O. (1998-2012). Mplus user's guide (7th ed.). Los Angeles, CA: Muthén \& Muthén.

Netherlands Organisation for International Cooperation in Higher Education. (2011). Grading systems in the Netherlands, the United States and the United Kingdom. Retrieved from http://www.nuffic.nl

Pekrun, R. (2006). The control-value theory of achievement emotions: Assumptions, corollaries, and implications for educational research and practice. Educational Psychology Review, 18, 315-341. doi:10.1007/ s10648-006-9029-9

Pekrun, R., Goetz, T., Frenzel, A. C., Barchfeld, P., \& Perry, R. P. (2011). Measuring emotions in students' learning and performance: The Achievement Emotions Questionnaire (AEQ). Contemporary Educational Psychology, 36, 36-48. doi:10.1016/j.cedpsych.2010.10.002

Pekrun, R., Goetz, T., Titz, W., \& Perry, R. P. (2002). Academic emotions in students' self-regulated learning and achievement: A program of qualitative and quantitative research. Educational Psychologist, 37, 91105. doi:10.1207/S15326985EP3702 4

Pekrun, R., \& Linnenbrink-Garcia, L. (2012). Academic emotions and student engagement. In S. L. Christenson, A. L. Reschly, \& C. Wylie (Eds.), Handbook of research on student engagement (pp. 259-282). New York, NY: Springer. doi:10.1007/978-1-4614-2018-7_12

Preacher, K. J., \& Hayes, A. F. (2008). Asymptotic and resampling strategies for assessing and comparing indirect effects in multiple mediator models. Behavior Research Methods, 40, 879-891. doi:10.3758/ BRM.40.3.879

Preacher, K. J., Rucker, D. D., \& Hayes, A. F. (2007). Addressing moderated mediation hypotheses: Theory, methods, and prescriptions. Multivariate Behavioral Research, 42, 185-227. doi:10.1080/00273170701341316

Pulfrey, C., Buchs, C., \& Butera, F. (2011). Why grades engender performance-avoidance goals: The mediating role of autonomous motivation. Journal of Educational Psychology, 103, 683-700. doi:10.1037/ a0023911

Robertson, J. S. (2000). Is attribution training a worthwhile classroom intervention for K-12 students with learning difficulties? Educational Psychology Review, 12, 111-134. doi:10.1023/A:1009089118008

Rozendaal, J. S., Minnaert, A., \& Boekaerts, M. (2001). Motivation and self-regulated learning in secondary vocational education: Informationprocessing type and gender differences. Learning and Individual Differences, 13, 273-289. doi:10.1016/S1041-6080(03)00016-5

Rudolph, K. D. (2002). Gender differences in emotional responses to interpersonal stress during adolescence. Journal of Adolescent Health, 30(4, Suppl 1), 3-13. doi:10.1016/S1054-139X(01)00383-4

Shim, S., \& Ryan, A. (2005). Changes in self-efficacy, challenge avoidance, and intrinsic value in response to grades: The role of achievement goals. Journal of Experimental Education, 73, 333-349. doi:10.3200/ JEXE.73.4.333-349

Skinner, E., Furrer, C., Marchand, G., \& Kindermann, T. (2008). Engagement and disaffection in the classroom: Part of a larger motivational dynamic? Journal of Educational Psychology, 100, 765-781. doi $10.1037 / \mathrm{a} 0012840$

Skinner, E. A., Wellborn, J. G., \& Connell, J. P. (1990). What it takes to do well in school and whether I've got it: A process model of perceived control and children's engagement and achievement in school. Journal of Educational Psychology, 82, 22-32. doi:10.1037/0022-0663.82.1.22

Tangney, J. P., \& Dearing, R. L. (2003). Shame and guilt. New York, NY: Guilford Press.

Tellegen, A., Watson, D., \& Clark, L. A. (1999). On the dimensional and hierarchical structure of affect. Psychological Science, 10, 297-303. doi:10.1111/1467-9280.00157

Trautwein, U., Lüdtke, O., Marsh, H. W., Koller, O., \& Baumert, J. (2006). Tracking, grading, and student motivation: Using group composition and status to predict self-concept and interest in ninth-grade mathematics. Journal of Educational Psychology, 98, 788-806. doi:10.1037/00220663.98.4.788

Tulis, M., \& Fulmer, S. M. (2013). Students' motivational and emotional experiences and their relationship to persistence during academic challenge in mathematics and reading. Learning and Individual Differences, 27, 35-46. doi:10.1016/j.lindif.2013.06.003

Turner, J. E., \& Schallert, D. L. (2001). Expectancy-value relationships of shame reactions and shame resiliency. Journal of Educational Psychology, 93, 320-329. doi:10.1037/0022-0663.93.2.320

Wampler, R. S., Munsch, J., \& Adams, M. (2002). Ethnic differences in grade trajectories during the transition to junior high. Journal of School Psychology, 40, 213-237. doi:10.1016/S0022-4405(02)00098-5

Wang, M., Willett, J. B., \& Eccles, J. S. (2011). The assessment of school engagement: Examining dimensionality and measurement invariance by gender and race/ethnicity. Journal of School Psychology, 49, 465-480. doi:10.1016/j.jsp.2011.04.001

Watson, D., Clark, L. A., \& Tellegen, A. (1988). Development and validation of brief measures of positive and negative affect: The PANAS scales. Journal of Personality and Social Psychology, 54, 1063-1070. doi:10.1037/0022-3514.54.6.1063 
Watson, D., Wiese, D., Vaidya, J., \& Tellegen, A. (1999). The two general activation systems of affect: Structural findings, evolutionary considerations, and psychobiological evidence. Journal of Personality and Social Psychology, 76, 820-838. doi:10.1037/0022-3514.76 .5 .820

Weiner, B. (1985). An attributional theory of achievement motivation and emotion. Psychological Review, 92, 548-573. doi:10.1037/0033-295X 92.4.548

Weiner, B. (2010). The development of an attribution-based theory of motivation: A history of ideas. Educational Psychologist, 45, 28-36. doi:10.1080/00461520903433596

Wigfield, A., \& Eccles, J. S. (2000). Expectancy-value theory of achievement motivation. Contemporary Educational Psychology, 25, 68-81. doi:10.1006/ceps.1999.1015
Wigfield, A., Tonks, S., \& Klauda, S. (2009). Expectancy-value theory. In K. Wentzel \& A. Wigfield (Eds.), Handbook of motivation at school (pp. 55-76). New York, NY: Routledge.

Yeager, D. S., \& Walton, G. M. (2011). Social-psychological interventions in education. Review of Educational Research, 81, 267-301. doi: $10.3102 / 0034654311405999$

You, S., \& Sharkey, J. (2009). Testing a developmental-ecological model of student engagement: A multilevel latent growth curve analysis. Educational Psychology, 29, 659-684. doi:10.1080/ 01443410903206815

Zanobini, M., \& Usai, M. C. (2002). Domain-specific self-concept and achievement motivation in the transition from primary to low middle school. Educational Psychology, 22, 203-217. doi:10.1080/ 01443410120115265

\section{Appendix}

\section{Model Fits for Models With Behavioral and Emotional Engagement at Time 1 and Time 3 Testing for Strict} Factorial Invariance

\begin{tabular}{lccccccc}
\hline \multicolumn{1}{c}{ Model } & $\chi^{2}$ & $d f$ & $p$ & CFI & $\Delta$ CFI & RMSEA & 90\% CI RMSEA \\
\hline Unconstrained & 117.9 & 42 & $<.001$ & .968 & & .064 & $.051 ; .078$ \\
Weak invariance & 120.7 & 46 & $<.001$ & .968 & .000 & .061 & $.048 ; .074$ \\
Strong invariance & 139.6 & 50 & $<.001$ & .962 & .006 & .064 & $.052 ; .077$ \\
Strict invariance & 146.9 & 56 & $<.001$ & .962 & .000 & .061 & $.049 ; .073$ \\
\hline
\end{tabular}

Note. $\mathrm{CFI}=$ comparative fit index; RMSEA $=$ root-mean-square error of approximation; $\mathrm{CI}=$ confidence interval. 